Cite this: Dalton Trans., 2014, 43, 7911

Received 21st February 2014, Accepted 7th March 2014

DOI: $10.1039 / c 4 d t 00553 h$

www.rsc.org/dalton

\title{
The first ruthenium-silsesquioxyl complexes - synthesis, structure and mechanistic implications in silylative coupling $\dagger$
}

\author{
Patrycja Żak, Maciej Kubicki, Bogdan Marciniec, ${ }^{\star}$ Szymon Rogalski, \\ Cezary Pietraszuk and Dawid Frąckowiak
}

\begin{abstract}
The first ruthenium-silsesquioxyl complexes have been synthesised and characterized via spectroscopic and X-ray methods. Mechanistic studies were performed and the complexes obtained were proved to be intermediates in the catalytic cycle of silylative coupling of olefins with vinylsilsesquioxane. Moreover, a mechanism for silylative coupling of styrene with vinylsilsesquioxanes was proposed.
\end{abstract}

\section{Introduction}

Polyhedral oligosilsesquioxanes (POSS) of the general formula $\left(\mathrm{RSiO}_{3 / 2}\right)_{n}$ and particularly those $(n=8)$ containing the inorganic cubic core of $\mathrm{Si}-\mathrm{O}-\mathrm{Si}$ bonds form a class of versatile building blocks for the production of inorganic-organic materials thanks to the three-dimensional highly symmetrical nature of the POSS core. ${ }^{1}$ The properties of the core permit a wide range of technological applications of silsesquioxanes that can be used as nanofillers for the preparation of nanostructured composites, catalysts, ${ }^{2-4}$ and dendrimers, ${ }^{5}$ as precursors for optoelectronic materials, ${ }^{6-9}$ as dry resists in microelectronics ${ }^{10}$ and as precursors for SiO deposition. ${ }^{11}$

Mono- and octa-functionalized silsesquioxanes and spherosilicates have been synthesized by TM catalyzed reactions such as hydrosilylation by $\mathrm{Si}-\mathrm{H}^{12}$ substituted POSS and silylative coupling ${ }^{13-16}$ by vinyl-substituted POSS with olefins, which occurs via intermediates containing a TM-silicon bond. The mechanism of silylative coupling of olefins with vinyl-substituted silicon compounds was the subject of our earlier study [see ref. 17; for reviews see ref. 18, 19]. So far only two reports have been published on the isolation and crystal structure of the complexes containing a TM-silicon bond (exactly cobaltsilicon bond). ${ }^{20,21}$

This paper reports the synthesis of the first silsesquioxyl complexes of ruthenium containing $\mathrm{Ru}-\mathrm{Si}$ bonds and describes the crystal structure of one of them. Moreover, the

Faculty of Chemistry, Adam Mickiewicz University, Umultowska 89b, 61-614 Poznan, Poland. E-mail: bogdan.marciniec@amu.edu.pl; Fax: (+48)61 8291508; Tel: $(+48) 618291366$

$\dagger$ CCDC 919730. For crystallographic data in CIF or other electronic format see DOI: $10.1039 / \mathrm{c} 4 \mathrm{dt} 00553 \mathrm{~h}$ catalytic activity of this complex in the silylative coupling of vinylheptaalkylsilsesquioxane with styrenes is analysed.

\section{Results and discussion}

When a toluene solution of the ruthenium hydride complex $\left[\mathrm{RuHCl}(\mathrm{CO})\left(\mathrm{PPh}_{3}\right)_{3}\right] 1$ was heated in the presence of 1 equiv. of vinylheptaisobutylsilsesquioxane at $110{ }^{\circ} \mathrm{C}$ the color of the solution gradually turned yellow-brown within $48 \mathrm{~h}$. The ${ }^{1} \mathrm{H}$ NMR spectrum of the post-reaction mixture revealed disappearance of signals at $\delta=-6.60(\mathrm{dt}) \mathrm{ppm}$ characteristic of the $\mathrm{Ru}-\mathrm{H}$ bond, and formation of a new singlet at $\delta=5.25 \mathrm{ppm}$ which can be assigned to ethylene. Moreover, the appearance of a new singlet at $\delta=37.49 \mathrm{ppm}$ was observed in the ${ }^{31} \mathrm{P}$ NMR spectrum. On the basis of these observations, a general scheme for the synthesis of ruthenium-silsesquioxyl complexes was proposed (Scheme 1).

Further experiments led to the development of efficient synthetic procedures for the synthesis of silsesquioxyl complexes 3 and 4 (see ESI $\dagger$ ). The compounds were isolated in high yields ( $89 \%$ and $86 \%$ respectively) as pale yellow powders. The obtained products were fully characterized by ${ }^{1} \mathrm{H},{ }^{13} \mathrm{C},{ }^{29} \mathrm{Si}$, and ${ }^{31} \mathrm{P}$ NMR spectroscopy and high resolution mass spectrometry (see ESI $\uparrow$ ). Moreover the structure of complex (3) was confirmed via $\mathrm{X}$-ray analysis (Fig. 1). Single crystals were

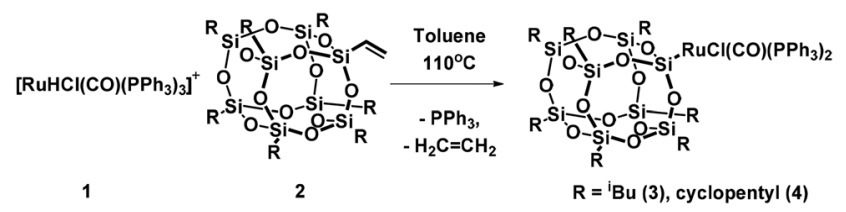

Scheme 1 Synthesis of ruthenium-silsesquioxyl complexes. 


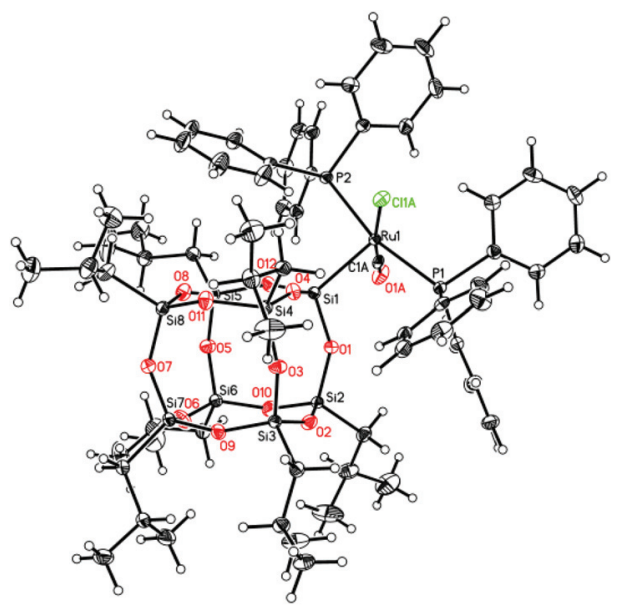

Fig. 1 A perspective view of complex 3, the ellipsoids are drawn at the $33 \%$ probability level. Hydrogen atoms are drawn as spheres of arbitrary radii. Some relevant geometrical parameters ( $\AA$, ' ; values for lessoccupied part are given in square brackets): Ru1-C1 1.793(4) [1.690(16)], Ru1-Cl1 2.4229(9) [2.491(5)], Ru1-Si1 2.2992(6), Ru1-P1 2.3944(5), Ru1P2 2.3572(5), C1-O1 1.166(5) [1.19(2)], <Si-O> 1.624(11), Cl1-Ru1-C1 170.55(10) [171.1(5)], P1-Ru1-P2 165.16(2).

obtained by slow evaporation of a pentane solution. $\mathrm{Ru}$ is 5 -coordinated in a square-pyramidal fashion. Four atoms, P1, P2, $\mathrm{Cl} 1$ and $\mathrm{C} 1$, are almost coplanar (maximum deviation from the least-squares plane is $0.053(3) \AA)$ while the fifth one, Si1, is $2.485 \AA$ out of this plane. The Ru atom is also slightly displaced, by $0.0219 \AA$, from the basal plane towards the apical Si1. Because of static disorder, in approximately one of six molecules the $\mathrm{CO}$ and $\mathrm{Cl}$ ligands are interchanged ( $c f$. Experimental part) without a significant influence on the complex geometry. The $\mathrm{Si}_{8} \mathrm{O}_{12}$ moiety is quite regular, with deviations from the ideal symmetry caused mainly by the presence of $\mathrm{Ru}$ coordination. The Si-O distances involving the coordinated silicon atom are systematically longer than the other $\mathrm{Si}-\mathrm{O}$ bonds; the mean values are 1.636(4) $\AA$ for Si1 and 1.620(5) $\AA$ for all other ones. In fact, Si1-O distances are the three longest $\mathrm{Si}-\mathrm{O}$ distances in the molecule. Also, the majority (8 of 12) of $\mathrm{Si-O}-\mathrm{Si}$ angles are within quite a narrow range, with the mean value of $145.4(16)^{\circ}$, while the other four $(\mathrm{O} 4, \mathrm{O} 8, \mathrm{O} 9, \mathrm{O} 10)$ are significantly larger, $154^{\circ}-161^{\circ}$.

\section{Stoichiometric reactions of the ruthenium-silsesquioxyl complex with styrene}

As we previously demonstrated for the silylative coupling mechanism of vinylsilicon compounds and olefins, complexes 3 and $\mathbf{4}$ can be treated as intermediate ones in the catalytic cycle. In order to better understand the mechanism of silylative coupling of styrenes with vinylsilsesquioxanes an equimolar reaction between ruthenium-silsesquioxyl complex 3 and styrene was performed (Scheme 2).

The tests were monitored by ${ }^{1} \mathrm{H}$ NMR spectroscopy. Addition of 1 equiv. of styrene and 5 equiv. of $\mathrm{CuCl}$ to the solution of complex 3 followed by heating the reacting mixture at $110{ }^{\circ} \mathrm{C}$ resulted in formation of the cross-coupling product 6 .

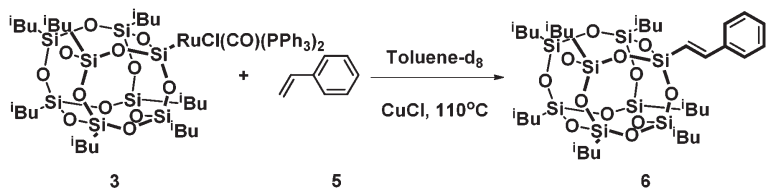

Scheme 2 Stoichiometric reactions of styrene with ruthenium-silsesquioxyl complexes.

Although spectroscopic examination does not confirm the formation of a complex 9 containing a $\mathrm{Ru}-\mathrm{H}$ bond, we observed signals at $\delta=6.47 \mathrm{ppm}(\mathrm{d}, 1 \mathrm{H}, J=19.2 \mathrm{~Hz},=\mathrm{CHSi})$ and $\delta=$ $7.56 \mathrm{ppm}(\mathrm{d}, 1 \mathrm{H}, J=19.2 \mathrm{~Hz},=\mathrm{CHPh})$ characteristic of product 6 . The intermediate complex containing a $\mathrm{Ru}-\mathrm{H}$ bond was also not observed in the reaction of $\mathrm{Ru}-\mathrm{Si}$ complexes with olefins, which was previously reported by our group. ${ }^{18,19}$ Moreover, GC-MS analysis confirmed the formation of the desired coupling product $\mathbf{6}$. Formation of compound $\mathbf{6}$ is evidence for insertion of styrene into the $\mathrm{Ru}-\mathrm{Si}(\mathrm{POSS})$ bond in complex 3 followed by $\beta-\mathrm{H}$ elimination and evolution of $E$-phenyl(silyl)ethene.

In the above stoichiometric reaction, the desired product was formed only when the reaction was conducted in the presence of $\mathrm{CuCl}$. Moreover, complex 3 exhibited almost no reactivity when the reaction was performed without $\mathrm{Cu}(\mathrm{I})$ salt. To better understand the role of $\mathrm{CuCl}$ in the reaction mixture we performed a series of stoichiometric reactions monitored by ${ }^{1} \mathrm{H}$ and ${ }^{31} \mathrm{P}$ NMR spectroscopy. When a toluene solution of the ruthenium-silsesquioxyl complex $\left[\mathrm{Ru}(\mathrm{POSS}) \mathrm{Cl}(\mathrm{CO})\left(\mathrm{PPh}_{3}\right)_{2}\right] \quad 3$ was heated in the presence of 5 equiv. of $\mathrm{CuCl}$ at $110{ }^{\circ} \mathrm{C}$ for $24 \mathrm{~h}$ we observed disappearance of the signals at $\delta=$ 37.49 ppm characteristic of complex 3 and formation of a new singlet at $\delta=25.95 \mathrm{ppm}$ in the ${ }^{31} \mathrm{P}$ NMR spectrum (Fig. 2).

The formation of this new complex 8 was accompanied by precipitation of an insoluble grey-brown $\left[\mathrm{CuPPh}_{3}\right]$ complex, whose appearance proves the dissociation of phosphine in the

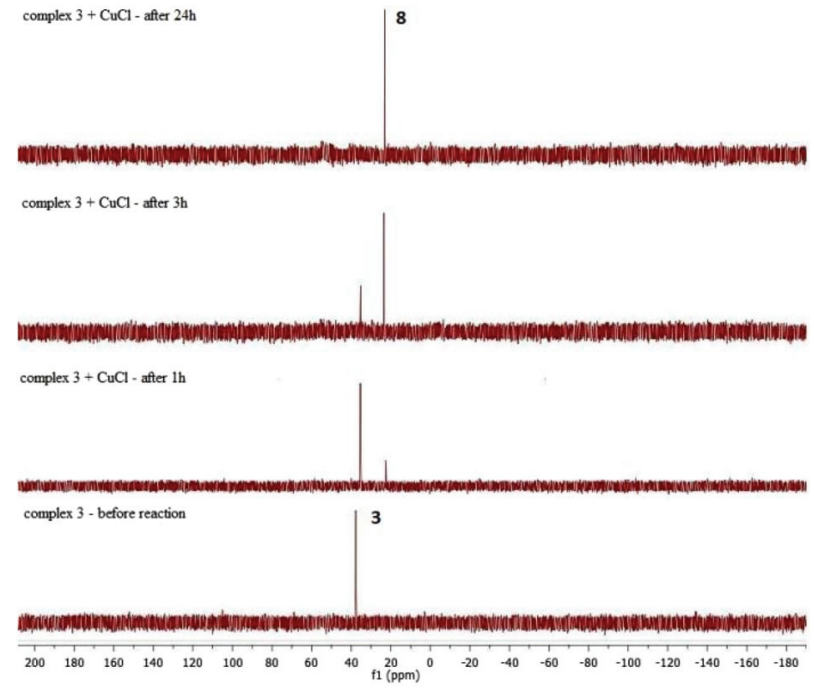

Fig. $2{ }^{31} \mathrm{P}$ NMR spectra of the stoichiometric reaction of 3 with $\mathrm{CuCl}$. 
proposed reaction system. The ${ }^{1} \mathrm{H}$ NMR spectrum of the postreaction mixture revealed changes in the aliphatic region. We observed disappearance of two multiplets at 1.85-2.06 and 2.06-2.31 and formation of a new multiplet at $2.15-2.38 \mathrm{ppm}$. All attempts to isolate this new complex 8 from the post-reaction mixture failed. However, the obtained results indicate that as a consequence of addition of $\mathrm{CuCl}$ to the reaction system, phosphine undergoes dissociation, as proved by $[\mathrm{CuClPPh}$ ] complex precipitation, and a new four-coordinated intermediate complex $\mathbf{8}$ is formed. The addition of $\mathrm{CuCl}$ is needed because of a large steric hindrance in the intermediate complex having the $\mathrm{Ru}-\mathrm{Si}(\mathrm{POSS})$ bond. The presence of the steric hindrance in the intermediate complex is supported by the fact that in the analogous silyl complex $\left[\mathrm{RuSiMe}_{3} \mathrm{Cl}(\mathrm{CO})\left(\mathrm{PPh}_{3}\right)_{2}\right]$ the insertion of styrene is effective without the addition of $\mathrm{CuCl}^{17}$

\section{Isotopic labelling experiments}

In order to confirm that the coupling process in the presence of 3 proceeds via the insertion-elimination mechanism which is characteristic of a silylative coupling reaction, ${ }^{17-19}$ we performed a series of labeling studies. In these experiments monitored by ${ }^{1} \mathrm{H}$ NMR spectroscopy, a solution of equimolar amounts of styrene- $\mathrm{d}_{8}$ and complex 3 was heated. The insertion-elimination mechanism should afford the formation of silylstyrene- $\mathrm{d}_{7}$ and ethylene- $\mathrm{d}_{1}$ (Scheme 3 ), at least in the initial stage of the reaction. ${ }^{1} \mathrm{H}$ NMR spectroscopic analysis of the products formed in the equimolar reaction carried out in the presence of 3 revealed the formation of $E$-1-phenyl-2-(silyl)ethene- $\mathrm{d}_{7}$ and ethylene- $\mathrm{d}_{1}$.

The results obtained in the experiments with deuterium labelled styrene clearly demonstrate that functionalisation of vinylsilsesquioxanes with styrenes proceeds according to the silylative coupling mechanism involving the activation of $=\mathrm{C}-\mathrm{H}$ and $\mathrm{Si}-\mathrm{C}=$ bonds.

\section{Catalytic examination and mechanistic implications}

The ruthenium-silsesquioxyl complex 3 was examined in the silylative coupling of selected styrenes with vinylheptaisobutylsilsesquioxane and its catalytic activity was compared to that of its parent complex $\left[\operatorname{RuHCl}(\mathrm{CO})\left(\mathrm{PPh}_{3}\right)_{3}\right] 1$ and the previously studied more reactive complex $\left[\mathrm{RuHCl}(\mathrm{CO})\left(\mathrm{PCy}_{3}\right)_{2}\right] 7$ (Scheme 4). ${ }^{15}$

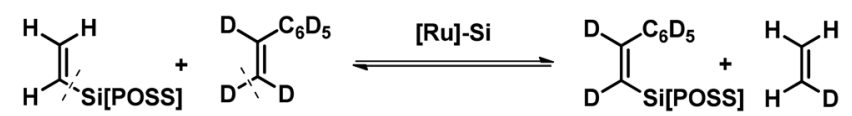

Scheme 3 Labeling experiments in the presence of complex 3.

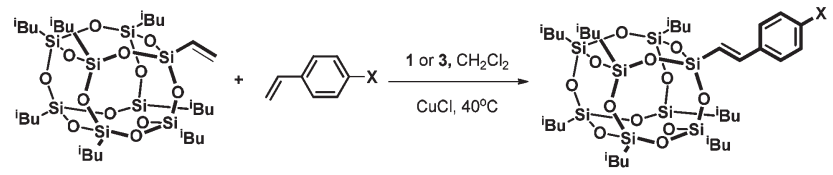

Scheme 4 Silylative coupling of vinylheptaisobutylsilsesquioxane with styrenes.
Table 1 Silylative coupling of vinylheptaisobutylsilsesquioxane with styrenes in the presence of 1,3 and 7 with a co-catalyst (CuCl)

\begin{tabular}{llc}
\hline & Catalyst & $\begin{array}{l}\text { Yield of } \\
\text { silylstyrene [\%] }\end{array}$ \\
\hline $\mathrm{H}$ & 3 & 33 \\
& 1 & 6 \\
$\mathrm{OMe}$ & 7 & $100^{a}$ \\
& 3 & 35 \\
$\mathrm{Cl}$ & $\mathbf{1}$ & 7 \\
& 7 & $100^{a}$ \\
$\mathrm{Br}$ & $\mathbf{3}$ & 32 \\
& $\mathbf{1}$ & 6 \\
& 3 & $100^{a}$ \\
& 1 & 34 \\
& 7 & 5 \\
& & $100^{a}$
\end{tabular}

Reaction conditions: $\mathrm{CH}_{2} \mathrm{Cl}_{2}$, reflux, argon, $5 \mathrm{~h} \quad[\mathrm{Ru}]$ : $\left[\mathrm{H}_{2} \mathrm{C}=\mathrm{CHSiR}_{3}\right]:[$ styrene $]=10^{-2}: 1: 3,[\mathrm{Ru}]: \mathrm{CuCl}=1: 5 .{ }^{a}$ Ref. 15.

Selected data for $\mathbf{1}$ and 3 are presented in Table 1, entry 1. As indicated in this table, the silsesquioxyl catalyst 3 exhibits higher catalytic activity than catalyst 1. For example after five hours in the reaction of vinylsilsesquioxane with styrene catalysed by $\mathbf{3}$, the conversion of the silsesquioxane reached $33 \%$, while the reaction catalysed by 1 revealed almost no conversion (6\%). The activity of catalysts $\mathbf{1}$ and $\mathbf{3}$ was examined in a wide temperature range. Our experiments demonstrated that increasing the temperature of the reacting mixture from $40^{\circ} \mathrm{C}$ to $110{ }^{\circ} \mathrm{C}$ did not give a higher yield of the coupling product. We compared the catalytic activity of complexes 1 and 3 with that of complex 7 bearing $\mathrm{PCy}_{3}$ ligands. In all cases, complex 7 was the most active in silylative coupling of vinylheptaisobutylsilsesquioxane with styrenes; however, because of its high reactivity we were unable to isolate ruthenium-silsesquioxyl complex bearing $\mathrm{PCy}_{3}$ ligands.

\section{Mechanistic implications}

On the basis of stoichiometric experiments and labelling studies we proposed a mechanism for the coupling of styrenes with vinylsilsesquioxanes in the presence of $[\mathrm{RuHCl}(\mathrm{CO})$ $\left.\left(\mathrm{PPh}_{3}\right)_{3}\right] \mathbf{1}$ and $\mathrm{CuCl}$ as co-catalysts (Fig. 3).

Our studies have shown that the coupling reaction proceeds according to the well-recognized insertion-elimination mechanism $^{17}$ in which, in the first step, vinylsilsesquioxane reacts with hydride complex 1 to give $\beta$-silylethyl complex. This compound decomposes via $\beta$-silsesquioxyl group migration to ruthenium and evolution of ethylene to give Ru-Si[POSS] complex 3 . Addition of $\mathrm{CuCl}$ to complex 3 causes dissociation of phosphine to produce a less sterically hindered four-coordinate complex $\mathbf{8}$ which reacts with styrene. The next step of the catalytic cycle involves the migratory insertion of styrene into a $\mathrm{Ru}-\mathrm{Si}$ bond, followed by $\beta$-H elimination to give $E$-phenyl(silyl)ethene 6 .

\section{Experimental}

\section{General methods and chemicals}

Unless mentioned otherwise, all operations were performed by using standard Schlenk techniques. ${ }^{1} \mathrm{H}$ - and ${ }^{13} \mathrm{C}-\mathrm{NMR}$ spectra 


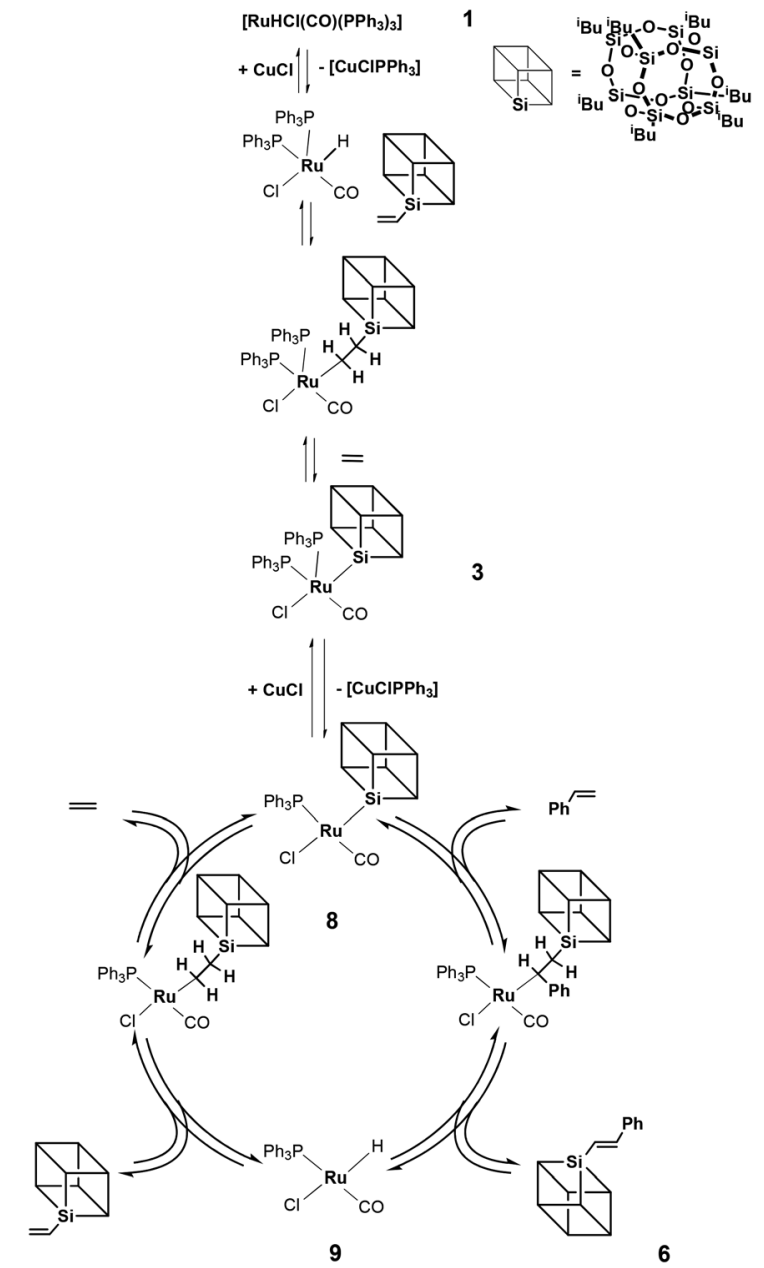

Fig. 3 Mechanism of silylative coupling of styrene with vinylsilsesquioxane.

were recorded on a Varian 400 operating at 402.6 and 101.2 MHz, respectively. ${ }^{31} \mathrm{P}$ NMR spectra were recorded on a Mercury 300 operating at 121.5 MHz. ${ }^{29} \mathrm{Si}$ NMR spectra were recorded on a Varian Avance 600 operating at $119.203 \mathrm{MHz}$. All FT-IR spectra were recorded with IFS 113v FT-IR and VERTEX 70 spectrophotometers (Bruker, Karlsruhe). GC analyses were carried out on a Varian CP-3800 (column: Rtx-5, 30 m, I.D. $0.53 \mathrm{~mm}$ ) equipped with TCD. Mass spectrometry analyses were performed using a Synapt G2-S mass spectrometer (Waters) equipped with an electrospray ion source and a quadrupole-time-of-flight mass analyzer. Acetonitrile was used as a solvent. The measurements were performed in positive ion mode with the desolvation gas flow $200 \mathrm{~L} \mathrm{~h}^{-1}$ and capillary voltage set to $5000 \mathrm{~V}$ with the flow rate of $20 \mu \mathrm{l} \mathrm{min}^{-1}$.

The chemicals were obtained from the following sources: vinyltrichlorosilane from ABCR, dichloromethane, acetone, $n$-pentane, ethanol, dichloromethane- $\mathrm{d}_{2}$, benzene- $\mathrm{d}_{6}$, toluene- $\mathrm{d}_{8}$, styrene- $\mathrm{d}_{8}$, decane, dodecane, styrene, 4-chlorostyrene, 4-bromostyrene, 4-methoxystyrene, 2-methoxyethanol, triphenylphosphine, formaldehyde, copper(I) chloride, anthracene, calcium hydride and anhydrous magnesium sulphate from Aldrich, triethylamine and silica gel 60 from Fluka, ruthenium(III) chloride hydrate from Lancaster, trisilanolisobutyl POSS from Hybrid Plastics, ${ }^{22}$ and toluene and $n$-hexane from Chempur. $\left[\mathrm{RuHCl}(\mathrm{CO})\left(\mathrm{PPh}_{3}\right)_{3}\right]$ was prepared according to the literature procedure. $^{23}$ Monovinylheptaisobutylsilsesquioxane was prepared according to the literature procedure. ${ }^{15}$ Monovinylheptacyclopentylsilsesquioxane was prepared using the same procedure. All solvents were dried prior to use over $\mathrm{CaH}_{2}$ and stored under argon. $\mathrm{CH}_{2} \mathrm{Cl}_{2}$ was additionally passed through a column with alumina and after that it was degassed by repeated freeze-pump-thaw cycles.

\section{Synthesis and characterization of ruthenium-silyl complexes}

Synthesis and characterization of complex 3. A $50 \mathrm{~mL}$ highpressure Schlenk vessel connected to gas and vacuum lines was charged under argon with $0.2 \mathrm{~g}\left(2.1 \times 10^{-4} \mathrm{~mol}\right)$ of [RuHCl$\left.(\mathrm{CO})\left(\mathrm{PPh}_{3}\right)_{3}\right]$ and $20 \mathrm{~mL}$ of dry toluene. The mixture was warmed in an oil bath to $110{ }^{\circ} \mathrm{C}$ and stirred for 15 minutes. Subsequently, monovinylheptaisobutylsilsesquioxane $(0.177 \mathrm{~g}$, $2.1 \times 10^{-4} \mathrm{~mol}$ ) was added to the reacting mixture and the suspension was refluxed for $48 \mathrm{~h}$ to give a yellow-brown solution. After this time the solvent was evaporated under vacuum, and $n$-hexane $(5 \mathrm{~mL})$ was added to the remaining contents to form a yellow precipitate. Then the resulting solution was decanted from the precipitate and the solid obtained was dried under vacuum (isolated yield $=89 \%$ ).

Analytical data: ${ }^{1} \mathbf{H}$ NMR $\left(\mathrm{C}_{6} \mathrm{D}_{6}, \delta, \mathrm{ppm}\right): 0.35-0.53(\mathrm{~m}, 14 \mathrm{H}$, $\left.\mathrm{CH}_{2}\right), 0.81-1.27\left(\mathrm{~m}, 42 \mathrm{H}, \mathrm{CH}_{3}\right), 1.85-2.06(\mathrm{~m}, 3 \mathrm{H}, \mathrm{CH})$, 2.06-2.31 (m, 4H, CH), 6.99-7.30 (m, 12H, Ph), 7.72-7.93 (m, $18 \mathrm{H}, \mathrm{Ph}) ;{ }^{13} \mathrm{C}$ NMR $\left(\mathrm{C}_{6} \mathrm{D}_{6}, \delta, \mathrm{ppm}\right): 23.05,23.25,23.44,23.62$, $23.81,24.72,24.75,24.78,26.15,26.20,26.27,26.38,26.43$, $30.45,128.78(\mathrm{t}, J=5.0 \mathrm{~Hz}), 130.49,131.83(\mathrm{~d}, J=2.5 \mathrm{~Hz})$, 132.61, 132.70, 132.85, 133.07, 133.29, $135.59(\mathrm{t}, J=5.8 \mathrm{~Hz})$, 200.70; ${ }^{29} \mathrm{Si}$ NMR: $\left(\mathrm{C}_{6} \mathrm{D}_{6}, \delta, \mathrm{ppm}\right):-66.05(\mathrm{Ru}-\mathrm{Si}),-67.32$, -69.60 (core); ${ }^{31} \mathbf{P}$ NMR: $\left(\mathrm{C}_{6} \mathrm{D}_{6}, \delta, \mathrm{ppm}\right): 37.49$; IR $\left(\nu, \mathrm{cm}^{-1}\right)$ : 1931 (CO); MS (FD): $m / z$ (\%): 1231.24 (31), 1263.20 (37), 1264.20 (61), 1265.20 (99), 1267.20 (100), 1268.20 (67), 1269.20 (50), 1275.23 (30), 1287.25 (42), 1288.24 (63), 1289.25 (97), 1290.24 (80), 1292.24 (55), 1299.09 (35), 1300.09 (30), 1465.13 (33), 1466.13 (40), 1467.13 (45), 1469.13 (42), 1470.13 (30), 1525.29 (38), 1526.29 (60), 1527.29 (95), 1529.29 (100), 1530.29 (77), 1531.29 (60), 1532.29 (33), 1543.29 (31), 1551.32 (39), 1552.32 (47), 1553.32 (62), 1554.32 (51), 1555.32 (47), 1556.32 (34), 1565.34 (38), 1566.33 (61), 1567.32 (92), 1568.33 (81), 1570.34 (57), 1571.33 (37), 1715.03 (33), 1717.03 (38), 1719.03 (34), 1803.38 (34), 1804.38 (54), 1805.37 (91), 1806.38 (93), 1807.38 (100), 1808.37 (82), 1809.38 (62), 1810.37 (37); HRMS (FD) for $\mathrm{C}_{65} \mathrm{H}_{93} \mathrm{ClO}_{13} \mathrm{P}_{2} \mathrm{RuSi}_{8} \mathrm{Na}$ : calc. 1527.2875; found: 1527.2871.

Synthesis and characterization of complex 4. Complex 4 was prepared using the same procedure and the following reagents: $\left[\mathrm{RuHCl}(\mathrm{CO})\left(\mathrm{PPh}_{3}\right)_{3}\right]\left(0.2 \mathrm{~g}, 2.1 \times 10^{-4} \mathrm{~mol}\right)$ and monovinylheptacyclopentylsilsesquioxane $(0.1948 \mathrm{~g}, 2.1 \times$ $10^{-4} \mathrm{~mol}$ ). Finally, a yellow precipitate was obtained (isolated yield $=86 \%$ ). 
Analytical data: ${ }^{1} \mathbf{H}$ NMR $\left(\mathrm{C}_{6} \mathrm{D}_{6}, \delta\right.$, ppm): 0.64-2.2 (m, 72H, $\left.\mathrm{C}_{5} \mathrm{H}_{9}-\right)$, 6.68-7.95 (m, 30H, Ph); ${ }^{13} \mathrm{C}$ NMR $\left(\mathrm{C}_{6} \mathrm{D}_{6}, \delta, \mathrm{ppm}\right)$ : $23.10,23.19,27.21,27.45,27.56,27.59,27.80,27.83,27.86$, 28.07, 28.31, 128.47 (t, $J=4.5 \mathrm{~Hz}), 130.07,131.59(\mathrm{~d}, J=$ $2.5 \mathrm{~Hz}), 132.34,132.44,135.44(\mathrm{t}, J=5.8 \mathrm{~Hz}), 199.82 ;{ }^{29} \mathrm{Si}$ NMR: $\left(\mathrm{C}_{6} \mathrm{D}_{6}, \delta, \mathrm{ppm}\right):-48.47(\mathrm{Ru}-\mathrm{Si}),-66.14,-68.75$ (core); ${ }^{31} \mathbf{P}$ NMR: $\left(\mathrm{C}_{6} \mathrm{D}_{6}, \delta, \mathrm{ppm}\right): 38.47$; IR $\left(\nu, \mathrm{cm}^{-1}\right): 1932$ (CO); MS (FD): m/z (\%):1550.32 (24), 1551.33 (65), 1553.33 (100), 1554.33 (85), 1555.33 (82), 1556.33 (60), 1557.33 (37); HRMS (FD) for $\mathrm{C}_{72} \mathrm{H}_{93} \mathrm{O}_{13} \mathrm{P}_{2} \mathrm{RuSi}_{8}$ : calc. 1553.3289 ; found: 1553.3273 .

Procedure for equimolar reactions of ruthenium-silyl complex 3 with styrene. The stoichiometric reactions were performed in J-Young valve NMR tubes and controlled by ${ }^{1} \mathrm{H}$ NMR spectroscopy. In a typical procedure ruthenium complex 3 $0.015 \mathrm{~g}\left(9.96 \times 10^{-6} \mathrm{~mol}\right)$ and anthracene $0.0001 \mathrm{~g}$ (internal standard) were dissolved in $0.65 \mathrm{~mL}$ of toluene- $\mathrm{d}_{8}$. Then the ${ }^{1} \mathrm{H}$ NMR spectrum was recorded and $1.2 \mu \mathrm{L}\left(9.96 \times 10^{-6} \mathrm{~mol}\right)$ styrene was added under argon by a microliter syringe. Then the reaction mixture was warmed in an oil bath to $110{ }^{\circ} \mathrm{C}$ and $0.0049 \mathrm{~g}\left(4.98 \times 10^{-5} \mathrm{~mol}\right) \mathrm{CuCl}$ was added. The mixture was heated for $24 \mathrm{~h}$ and after this time the ${ }^{1} \mathrm{H}$ NMR spectrum of the reaction mixture was taken. The corresponding reactions with styrene- $\mathrm{d}_{8}$ were performed using the same procedure.

Procedure for stoichiometric reactions of ruthenium-silyl complex 3 with CuCl. The stoichiometric reactions were performed in J-Young valve NMR tubes and controlled by ${ }^{1} \mathrm{H}$ and ${ }^{31} \mathrm{P}$ NMR spectroscopy. In a typical procedure, ruthenium complex $30.01 \mathrm{~g}\left(6.64 \times 10^{-6} \mathrm{~mol}\right)$ and anthracene $0.0001 \mathrm{~g}$ (internal standard) were dissolved in $0.65 \mathrm{~mL}$ of toluene- $\mathrm{d}_{8}$. Then the ${ }^{1} \mathrm{H}$ and ${ }^{31} \mathrm{P}$ NMR spectra were recorded and $0.0032 \mathrm{~g}$ $\left(3.32 \times 10^{-5} \mathrm{~mol}\right) \mathrm{CuCl}$ was added under argon. Then the reaction mixture was heated at $110{ }^{\circ} \mathrm{C}$, and after $1 \mathrm{~h}, 3 \mathrm{~h}$ and $24 \mathrm{~h}$, the ${ }^{1} \mathrm{H}$ and ${ }^{31} \mathrm{P}$ NMR spectra of the reaction mixture were taken.

\section{General procedure for the catalytic examination}

The oven dried $5 \mathrm{~mL}$ glass reactor equipped with a condenser and a magnetic stirring bar was charged under argon with $2 \mathrm{~mL}$ of $\mathrm{CH}_{2} \mathrm{Cl}_{2}$, monovinylsilsesquioxane $\left(0.1 \mathrm{~g}, 1.19 \times 10^{-4}\right.$ $\mathrm{mol})$, styrene $\left(41 \mu \mathrm{L}, 3.56 \times 10^{-4} \mathrm{~mol}\right)$ and $20 \mu \mathrm{L}$ of an internal standard (decane or dodecane). The reaction mixture was placed in an oil bath and preheated to $40{ }^{\circ} \mathrm{C}$. Then ruthenium complex 1 or 3 (0.0011 g (complex 1) or $0.0017 \mathrm{~g}$ (complex 2), $1.19 \times 10^{-6} \mathrm{~mol}$ ) was added under argon. After $5 \mathrm{~min}$ of the reaction, copper(I) chloride $\left(0.0006 \mathrm{~g}, 5.93 \times 10^{-6} \mathrm{~mol}\right)$ was added. The reaction mixture was heated at $40{ }^{\circ} \mathrm{C}$ under a gentle flow of argon. Reaction yields were calculated on the basis of the ${ }^{1} \mathrm{H}$ NMR spectra of the reaction mixture. The corresponding reactions with 4-methoxystyrene, 4-bromostyrene and 4-chlorostyrene were performed using the same procedure.

\section{X-ray analysis (complex 3)}

X-ray diffraction data were collected at $100(1) \mathrm{K}$ by the $\omega$-scan technique, on an Agilent Technologies four-circle Xcalibur diffractometer equipped with an Eos detector ${ }^{24}$ with an $\mathrm{MoK}_{\alpha}$ radiation source $(\lambda=0.71073 \AA)$. The temperature was controlled with an Oxford Instruments Cryosystem device. The data were corrected for Lorentz-polarization effects as well as for absorption (multiscan). ${ }^{24}$ Accurate unit-cell parameters were determined by a least-squares fit of 12093 reflections of highest intensity, chosen from the whole experiment. The calculations were mainly performed within the WinGX program system. ${ }^{25}$ The structures were solved with SIR92 ${ }^{26}$ and refined with the full-matrix least-squares procedure on $F^{2}$ using SHELXL97. ${ }^{27}$ Scattering factors incorporated in SHELXL97 were used. The function $\sum \mathrm{w}\left(\left|F_{\mathrm{o}}\right|^{2}-\left|F_{\mathrm{c}}\right|^{2}\right)^{2}$ was minimized, with $\mathrm{w}^{-1}=\left[\sigma^{2}\left(F_{\mathrm{o}}\right)^{2}+(0.0313 P)^{2}+2.2712 P\right]$, where $P=\left[\operatorname{Max}\left(F_{\mathrm{o}}{ }^{2}, 0\right)+2 F_{\mathrm{c}}{ }^{2}\right] / 3$. All non-hydrogen atoms were refined anisotropically, hydrogen atoms from methyl groups were placed geometrically, in idealized positions, and refined as

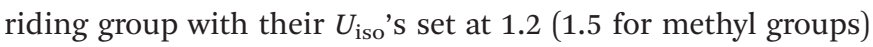
times $U_{\text {eq }}$ of the appropriate carrier atom. Disorder was detected during structure refinement: $\mathrm{Cl}$ and $\mathrm{CO}$ ligands are partially exchanged (site occupation factors 0.83/017), and in one iPr group the methyl groups are disordered over two positions (s.o.f.'s 0.70/0/30). Crystallographic data (excluding structure factors) for the structural analysis have been deposited with the Cambridge Crystallographic Data Centre, no. CCDC-919730.

Crystal data: $\mathrm{C}_{65} \mathrm{H}_{93} \mathrm{ClO}_{13} \mathrm{P}_{2} \mathrm{RuSi}_{8}, M_{\mathrm{r}}=1505.57$, triclinic, $P \overline{1}, a=13.4910(3) \AA, b=14.8072(3) \AA, c=19.0764(4) \AA, \alpha=$ $89.338(2)^{\circ}, \beta=81.060(2)^{\circ}, \gamma=77.729(2)^{\circ}, V=3677.57(13) \AA^{3}$, $F(000)=1580, d_{x}=1.36 \mathrm{~g} \mathrm{~cm}^{-3}, \mu\left(\mathrm{MoK}_{\alpha}\right)=0.48 \mathrm{~cm}^{-1}, 33625$ reflections measured, 14864 unique $\left(R_{\text {int }}=0.024\right), 12507$ with $I>2 \sigma(I)$. Final $R(\mathrm{obs})=0.031, R($ all $)=0.042, \mathrm{w} R_{2}(\mathrm{obs})=0.071$, $\mathrm{w} R_{2}($ all $)=0.075, S=1.04, \max / \min \Delta \rho$ in the final $\Delta F$ map:

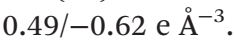

\section{Conclusions}

New silsesquioxyl ruthenium complexes (3 and 4) have been synthesized and their structures were confirmed by spectroscopic and X-ray methods. These complexes were proved to be intermediates in the silylative coupling of vinylsilsesquioxane with styrene. The reaction between vinylsilsesquioxanes and styrenes in the presence of ruthenium hydride complex 1 was confirmed to proceed via the insertion-elimination mechanism. Moreover, the obtained complex 3 exhibits higher catalytic activity than its parent hydride complex $\mathbf{1}$.

\section{Acknowledgements}

The authors gratefully acknowledge the financial support from the European Regional Development Fund, Operational Programme Innovative Economy, 2007-2013, project no. UDA-POIG.01.03.01-30-173/09 and from the National Science Centre (Poland) (project 'Maestro' no. UMO-2011/0/A/ST5/ 00472). 


\section{References}

1 (a) D. B. Cordes, P. D. Lickiss and F. Rataboul, Chem. Rev., 2010, 110, 2081; (b) S. Yamaguchi and K. Tamao, in Siliconcontaining polymers, ed. R. G. Jones, W. Ando and J. Chojnowski, Kluwer, 2000, ch. 17; (c) Materials Research Society Symposia Proceedings, ed. R. M. Laine, C. Sanchez, E. Giannelis and C. J. Brinker, Organic/Inorganic Hybrid Materials, Materials Research Society, Warrendale, 2000, vol. 628; (d) Materials Research Society Symposia Proceedings, ed. C. Sanchez, R. M. Laine, S. Yang and C. J. Brinker, Organic/Inorganic Hybrid Materials, Materials Research Society, Warrendale, 2002, vol. 726.

2 B. Marciniec, I. Kownacki, A. Franczyk and M. Kubicki, Dalton Trans., 2011, 40, 5073.

3 R. Duchateau, Chem. Rev., 2002, 102, 3626.

4 E. A. Quadrelli and J. M. Basset, Coord. Chem. Rev., 2000, 254, 707.

5 N. Mintcheva, M. Tanabe and K. Osakada, Organometallics, 2011, 30, 187.

6 A. R. Bassindale and T. E. Gentle, J. Mater. Chem., 1993, 3, 1319.

7 M. A. Wahab, K. Y. Mya and C. He, J. Polym. Sci., Part A: Polym. Chem., 2008, 46, 5887.

8 M. Y. Lo, C. Zhen, M. Lauters, G. E. Jabbour and A. Sellinger, J. Am. Chem. Soc., 2007, 129, 5808.

9 K. I. Chan, P. Sonar and A. Sellinger, J. Mater. Chem., 2009, 19, 9103.

10 A. Schmidt, S. Babin, K. Böhmer and H. W. P. Koops, Microelectron. Eng., 1997, 35, 129.

11 S. B. Desu, C. H. Peng, T. Shi and P. A. Agaskar, J. Electrochem. Soc., 1992, 139, 2682.
12 D. B. Cordes, P. D. Lickiss and F. Rataboul, Chem. Rev., 2010, 110, 2081.

13 Y. Itami, B. Marciniec and M. Kubicki, Chem. - Eur. J., 2004, 10, 1239.

14 J. Waehner, B. Marciniec and P. Pawluć, Eur. J. Inorg. Chem., 2007, 18, 2975.

15 P. Żak, C. Pietraszuk, B. Marciniec, G. Spólnik and W. Danikiewicz, Adv. Synth. Catal., 2009, 351, 2675.

16 P. Żak, B. Marciniec, M. Majchrzak and C. Pietraszuk, J. Organomet. Chem., 2011, 696, 887.

17 B. Marciniec and C. Pietraszuk, Organometallics, 1997, 16, 4320-4326.

18 B. Marciniec, Coord. Chem. Rev., 2005, 249, 2374-2390.

19 B. Marciniec, Acc. Chem. Res., 2007, 40, 943-952.

20 G. Calzaferri, R. Imhofa and K. W. Tornroosb, J. Chem. Soc., Dalton Trans., 1993, 3741.

21 M. Rattay, D. Fenske and P. Jutzi, Organometallics, 1998, 17, 2930.

22 Vinylsilsesquioxanes purchased from Hybrid Plastics Inc. and used as received do not undergo silylative coupling. Successful reactivity was achieved by preliminary purification by extraction of pentane solution of the reagent with water followed by drying of the organic phase with magnesium sulphate and solvent evaporation.

23 J. Levison and S. D. Robinson, J. Chem. Soc. A, 1970, 2947.

24 CrysAlis PRO, Agilent Technologies, 2010.

25 L. J. Farrugia, J. Appl. Crystallogr., 1999, 32, 837.

26 A. Altomare, G. Cascarano, C. Giacovazzo and A. Guagliardi, J. Appl. Crystallogr., 1993, 26, 343.

27 G. M. Sheldrick, Acta Crystallogr., Sect. A: Fundam. Crystallogr., 2008, 64, 112. 